\title{
Left Ventricular Speckle Tracking Echocardiography Changes Among Early-stage Breast Cancer Patients Three Years After Radiotherapy
}

\author{
SUVI SIRKKU TUOHINEN ${ }^{1,2}$, TANJA SKYTTA ${ }^{3,4}$, HEINI HUHTALA ${ }^{5}$, VESA VIRTANEN ${ }^{2}$, \\ PIRKKO-LIISA KELLOKUMPU-LEHTINEN ${ }^{3,4}$ and PEKKA RAATIKAINEN ${ }^{1}$ \\ ${ }^{1}$ Heart and Lung Center, Helsinki University Central Hospital and Helsinki University, Helsinki, Finland; \\ ${ }^{2}$ Faculty of Medicine and Life Sciences, Tampere University Hospital, \\ University of Tampere and Heart Center, Tampere, Finland; \\ ${ }^{3}$ Department of Oncology, Tampere University Hospital, Tampere, Finland; \\ ${ }^{4}$ Faculty of Medicine and Health Technology, Tampere University, Tampere, Finland; \\ ${ }^{5}$ Faculty of Social Sciences, University of Tampere, Tampere, Finland
}

\begin{abstract}
Background/Aim: Chest radiotherapy (RT) doubles late cardiac mortality. This study aimed to evaluate the evolution of cardiac changes in speckle tracking echocardiography during a three-year follow-up. Materials and Methods: This prospective study included 81 chemotherapy-naïve early-stage breast cancer patients who were evaluated at baseline, immediately after RT and three years after RT. Sixty-one patients had left-sided $(L S B C)$ and 20 right-sided breast cancer (RSBC). Results: Global longitudinal strain (GLS) declined from baseline $-18.0 \pm 3.3 \%$ to $-17.0 \pm 3.0 \%(p=0.015)$ at the three-year follow-up examination. A decline over $15 \%$ (GLS15) was observed in 19 (27\%) patients. GLS15 was independently associated with aromatase inhibitor use $(\beta=-1.977, p=0.001)$. In regional analysis, patients with $L S B C$ had apical strain decline by $3.2 \pm 5.5 \%(p<0.001)$ and patients with RSBC showed basal rotation decline by $1.8^{\circ}\left(-0.2^{\circ}, 3.8^{\circ}\right)(p=0.030)$. Conclusion: Even contemporary $R T$ induced progressive global and regional decline in speckle tracking analysis. The regional changes complied with RT fields.
\end{abstract}

Radiotherapy (RT) is an integral part of the treatment in half of cancer patients (1). Over $80 \%$ of early-stage breast cancer

This article is freely accessible online.

Correspondence to: Suvi Sirkku Tuohinen, $\mathrm{MD}, \mathrm{PhD}$, Heart and Lung Center, Helsinki University Central Hospital and Helsinki University, PO Box 340, 00029 Helsinki, Finland. Tel: +358 504270565, e-mail: suvi.tuohinen@ fimnet.fi

Key Words: Breast cancer, radiotherapy, speckle tracking echocardiography, midterm follow-up. patients receive adjuvant $\mathrm{RT}$, which reduces the local recurrence risk by half and, the late breast cancer-related mortality by a fifth. The overall survival of early-stage breast cancer patients at 5 years is $91 \%$ in Finland (www.cancerregistry.fi). However, RT induces adverse effects in healthy tissue, which may lead to late dysfunction in adjacent organs. The heart is an important organ at risk, especially in left-sided breast cancer (LSBC). Breast cancer RT increases cardiac mortality and morbidity almost twofold in long-term cohorts collected from patients treated with older RT techniques $(2,3)$. The modern RT treatment protocols have reduced cardiac radiation exposure. However, the clinical impact of the reduced cardiac dose will not be revealed until long-term data are available. In the meantime, early and mid-term cardiac changes are valuable in predicting later sequelae and to reveal the mechanism and time-course of RT-induced heart disease (RIDH).

RIHD can manifest as coronary artery disease, valvular lesions, heart failure, pericardial changes or conduction abnormalities. These changes occur usually several years or decades after RT treatment (2-4). The early subclinical RTinduced cardiac changes precede the late manifestations. Perfusion defects and changes in strain and strain rate corresponding to the RT fields have been detected 0-6 months after RT with myocardial perfusion imaging and with echocardiography (5-7). After chemotherapy, an early change in global longitudinal strain (GLS) predicts later decline in left ventricular ejection fraction (LVEF), but the knowledge of post-RT strain evolution is sparse $(8,9)$. The aim of our study was to explore the evolution of early RT-induced changes in speckle tracking echocardiography (STE) in early-stage breast cancer patients within the first three years after RT. 
Table I. Characteristics of the study group.

\begin{tabular}{|c|c|c|c|c|c|}
\hline & \multicolumn{2}{|c|}{$\begin{array}{l}\text { Patients with right-sided breast cancer } \\
\qquad \mathrm{n}=20\end{array}$} & \multicolumn{2}{|c|}{$\begin{array}{l}\text { Patients with left-sided breast cancer } \\
\qquad \mathrm{n}=61\end{array}$} & \multirow[b]{2}{*}{$p$-Value } \\
\hline & Md & {$\left[\mathrm{Q}_{1}, \mathrm{Q}_{3}\right]$} & $\mathrm{Md}$ & {$\left[\mathrm{Q}_{1}, \mathrm{Q}_{3}\right]$} & \\
\hline Age (years) & 64 & {$[60,66]$} & 64 & {$[58,67]$} & 0.789 \\
\hline \multirow[t]{2}{*}{ BMI $\left(\mathrm{kg} / \mathrm{m}^{2}\right)$} & 26.7 & {$[24.7,30.0]$} & 26.3 & {$[24.1,29.9]$} & 0.567 \\
\hline & $\mathrm{n}$ & $\%$ & $\mathrm{n}$ & $\%$ & \\
\hline \multicolumn{6}{|l|}{ Concurrent diagnosis } \\
\hline Hypertension & 13 & 65.0 & 22 & 36.7 & 0.038 \\
\hline Diabetes & 3 & 15.0 & 4 & 6.7 & 0.358 \\
\hline High cholesterol & 4 & 20.0 & 14 & 23.3 & 1.000 \\
\hline Hypothyreosis & 4 & 20.0 & 12 & 20.0 & 0.705 \\
\hline No concurrent other diagnosis & 5 & 25.0 & 28 & 46.7 & 0.118 \\
\hline \multicolumn{6}{|l|}{ Smoking } \\
\hline Current & 2 & 10.0 & 9 & 15.0 & 0.722 \\
\hline Ever & 4 & 20.0 & 16 & 26.7 & 0.767 \\
\hline \multicolumn{6}{|l|}{ Baseline medication } \\
\hline Beta blockers & 5 & 25.0 & 7 & 11.7 & 0.163 \\
\hline Calsium channel blockers & 4 & 20.0 & 4 & 6.7 & 0.102 \\
\hline ACE/ARB & 10 & 50.0 & 15 & 25.0 & 0.052 \\
\hline Statins & 4 & 20.0 & 12 & 20.0 & 1.000 \\
\hline \multicolumn{6}{|l|}{ Cancer treatment } \\
\hline \multicolumn{6}{|l|}{ Surgery } \\
\hline Breast cancer resection & 19 & 95.0 & 59 & 98.3 & 0.440 \\
\hline Breast cancer ablation & 1 & 5.0 & 1 & 1.7 & 0.440 \\
\hline \multicolumn{6}{|l|}{ Hormonal therapy } \\
\hline Use of AI & 8 & 40.0 & 22 & 36.7 & 0.796 \\
\hline \multirow[t]{2}{*}{ Use of tamoxifen } & 9 & 45.0 & 2 & 3.3 & 0.032 \\
\hline & $\mathrm{Md}$ & {$\left[\mathrm{Q}_{1}, \mathrm{Q}_{3}\right]$} & $\mathrm{Md}$ & {$\left[\mathrm{Q}_{1}, \mathrm{Q}_{3}\right]$} & \\
\hline \multicolumn{6}{|l|}{ Radiotherapy } \\
\hline Mean heart dose (Gy) & 0.6 & {$[0.4,0.7]$} & 3.1 & {$[1.8,4.0]$} & $<0.001$ \\
\hline
\end{tabular}

BMI: Body mass index; ACE/ARB: angiotensin converting enzyme inhibitors or angiotensin receptor blockers; AI: aromatase inhibitor; Gy: Gray. Significant $p$-values $(p<0.05)$ are shown in bold.

\section{Patients and Methods}

Patient selection. We included 81 eligible female patients with early-stage breast cancer into this single-center prospective study from July 2011 to November 2016. Sixty-one patients had left-sided (LSBC) and 20 patients had right-sided breast cancer (RSBC). All of the patients received adjuvant conformal three-dimensional (3D) RT after breast cancer surgery. The exclusion criteria have been described previously (7). Due to the early stage of the disease, no patient received chemotherapy. The study complied with the Helsinki Declaration, and the local institutional board of ethics approved the protocol (ETL R10160). All participants signed an informed consent before their enrollment.

Radiotherapy. RT was delivered according to normal institutional clinical guidelines either with 50 Gray (Gy) with 2 Gy fractions or 42.56 Gy with $2.66 \mathrm{~Gy}$ fractions as described in detail earlier (7).
Cardiac examinations. The patients were examined $6 \pm 8$ days prior to RT, within three days after the end of RT and again three years post-RT (range=2.5-3.3 years). All echocardiographic examinations were performed by the same cardiologist (SST) using a Philips iE33 ultrasound machine (Bothell, WA, USA) and with 1-5 MHz matrixarray X5-1 transducer according to a predefined protocol (7). All off-line analysis was performed with the same Philips Qlab 10.1 version (Philips Qlab, Bothell, WA, USA). The analysis of variability for intraobserver and interobserver tests as well as for test-retest for the global, regional and segmental strain analysis have been previously reported (7).

Statistics. The data are presented as the means with standard deviations (SD) for variables with normal distribution and as medians with quartiles for non-normally distributed variables or as numbers with percentages. The difference between groups was tested with independent samples $t$-test, Mann Whitney $U$-test and Chi square or 
Table II. Changes in global and regional strain in speckle tracking analysis in patients with left-sided breast cancer.

\begin{tabular}{|c|c|c|c|c|c|c|c|c|c|}
\hline & \multicolumn{2}{|c|}{$\begin{array}{c}\text { Baseline } \\
\mathrm{n}=54\end{array}$} & \multicolumn{2}{|c|}{$\begin{array}{c}\text { After RT } \\
\mathrm{n}=58\end{array}$} & \multicolumn{2}{|c|}{$\begin{array}{c}3 \text { years control } \\
n=60\end{array}$} & \multirow[b]{2}{*}{$p$-Value $^{1}$} & \multirow[b]{2}{*}{$p$-Value ${ }^{2}$} & \multirow[b]{2}{*}{$p$-Value ${ }^{3}$} \\
\hline & Mean & SD & Mean & SD & Mean & SD & & & \\
\hline \multicolumn{10}{|c|}{ Longitudinal strain } \\
\hline Global & -18.4 & 3.1 & -17.3 & 3.2 & -16.8 & 3.1 & 0.003 & 0.001 & 0.146 \\
\hline Basal & -21.6 & 5.0 & -23.2 & 4.9 & -24.1 & 6.2 & 0.024 & 0.003 & 0.246 \\
\hline Mid & -19.4 & 4.6 & -17.9 & 5.7 & -17.8 & 5.8 & 0.039 & 0.022 & 0.845 \\
\hline Apical & -18.6 & 5.1 & -16.8 & 4.8 & -15.4 & 4.5 & 0.003 & $<0.001$ & 0.028 \\
\hline Anterior & -18.3 & 4.3 & -17.7 & 4.5 & -17.8 & 3.4 & 0.277 & 0.375 & 0.967 \\
\hline Anteroseptal & -19.1 & 4.0 & -18.5 & 4.5 & -16.9 & 4.8 & 0.281 & 0.040 & 0.015 \\
\hline Inferoseptal & -21.2 & 3.7 & -20.2 & 3.9 & -19.9 & 4.7 & 0.110 & 0.137 & 0.787 \\
\hline Inferior & -20.4 & 4.0 & -19.6 & 4.9 & -18.5 & 4.8 & 0.264 & 0.037 & 0.253 \\
\hline Inferolateral & -20.0 & 4.8 & -19.0 & 4.8 & -20.0 & 4.3 & 0.122 & 0.732 & 0.090 \\
\hline Anterolateral & -20.5 & 3.5 & -20.4 & 4.4 & -20.9 & 3.8 & 0.874 & 0.979 & 0.587 \\
\hline \multicolumn{10}{|c|}{ Circumferential strain } \\
\hline Global & -30.1 & 4.7 & -29.1 & 5.2 & -29.7 & 5.2 & 0.072 & 0.158 & 0.593 \\
\hline Basal & -23.6 & 4.9 & -22.8 & 5.3 & -24.8 & 5.6 & 0.076 & 0.206 & 0.007 \\
\hline Mid & -30.3 & 6.2 & -30.2 & 6.0 & -30.7 & 5.7 & 0.525 & 0.646 & 0.845 \\
\hline Apical & -36.8 & 8.6 & -35.3 & 8.0 & -34.5 & 8.7 & 0.093 & 0.082 & 0.539 \\
\hline Anterior & -38.8 & 9.8 & -38.3 & 9.6 & -43.2 & 7.7 & 0.216 & 0.008 & $<0.001$ \\
\hline Anteroseptal & -33.1 & 6.8 & -31.3 & 7.6 & -29.2 & 6.3 & 0.085 & $<0.001$ & 0.048 \\
\hline Inferoseptal & -30.5 & 7.1 & -29.9 & 6.3 & -31.5 & 6.2 & 0.400 & 0.497 & 0.047 \\
\hline Inferior & -31.6 & 6.2 & -32.3 & 7.5 & -34.3 & 7.4 & 0.773 & 0.016 & 0.053 \\
\hline Inferolateral & -29.6 & 6.4 & -28.6 & 6.3 & -28.8 & 5.9 & 0.122 & 0.732 & 0.090 \\
\hline Anterolateral & -26.5 & 6.6 & -26.1 & 6.3 & -26.4 & 6.0 & 0.754 & 0.580 & 0.579 \\
\hline
\end{tabular}

RT: Radiotherapy. $p$-Value ${ }^{1}, p$-Value ${ }^{2}$ and $p$-Value ${ }^{3}$ present statistical significance of the changes in strain values between baseline and after RT, between baseline and at the 3 year follow-up examination and between values measured after RT and at the 3 year follow-up examination, respectively. Significant $p$-values $(p<0.05)$ are shown in bold.

Fisher's test for variables with normal and non-normal distribution and for categorical variables, respectively. The changes of the variables were tested with paired samples $t$-test, Wilcoxon signed rank test and related-samples McNemar's test when appropriate. Univariate and multivariable analysis was performed with linear (numerical data) or logistic regression model. Multivariable analysis was performed with forward stepwise analysis for age, hypertension, smoking history, the use of an angiotensin converting enzyme inhibitor (ACE) or angiotensin receptor blocker (ARB), the use of a statin, the use of an aromatase inhibitor (AI) and for mean heart radiation dose. The analysis was performed with IBM SPSS version 24 .

\section{Results}

General characteristics. The characteristics of the population are shown in Table I. The mean age of the patients at inclusion was 64 years (range $=49-83$ years). Thirty-three patients $(41 \%)$ had no other concurrent diagnosis, $60(74 \%)$ patients were non-smokers and $29(38 \%)$ patients had normal body mass index (BMI under $25 \mathrm{~kg} / \mathrm{m}^{2}$ ). The most prevalent concurrent diseases were hypertension (35 patients, $45 \%$ ) and dyslipidemia (19 patients, 24\%).

Regional analysis of the longitudinal strain. At three-year follow-up, the changes from baseline in the regional and segmental longitudinal strains were more prevalent in the patients with LSBC than in those with RSBC (Tables II and III, Figure 1). In patients with LSBC, the number of segments with a significant reduction increased from five segments immediately after RT to 7 segments at three-year follow-up, and were located in the apical and anteroseptal regions (Figure 1). Furthermore, there was a significant worsening of the longitudinal strain between post-RT and the three-year follow-up examination in the apical and anteroseptal regions, while the changes were maintained in the mid and inferior regions without significant change from post-RT to the three-year follow-up examination (Table II). The basal area of the left ventricle (LV) displayed increased function in both segmental and regional levels. Patients with RSBC had RT-induced reduction in the basal anterior segments throughout the follow-up period.

In the whole study population, the strain in the apical region (including the six apical segments and the apex) was $-17.9 \pm 5.3 \%$ at baseline, $-17.0 \pm 4.7 \%$ post-RT $(p<0.001$ baseline $v s$. post-RT) and $-15.8 \pm 4.5 \%$ at the three-year followup $(p=0.002$ baseline $v s$. three-year follow-up and $p=0.024$ post-RT $v s$. three-year control). There was a difference between patients with LSBC and RSBC. In patients with LSBC, the apical strain declined by $3.2 \pm 5.5 \%(p<0.001)$ while in patients 
Table III. Changes in global and regional strain in speckle tracking analysis in patients with right-sided breast cancer.

\begin{tabular}{|c|c|c|c|c|c|c|c|c|c|}
\hline & \multicolumn{2}{|c|}{$\begin{array}{c}\text { Baseline } \\
\mathrm{n}=20\end{array}$} & \multicolumn{2}{|c|}{$\begin{array}{c}\text { After RT } \\
n=20\end{array}$} & \multicolumn{2}{|c|}{$\begin{array}{c}3 \text { years control } \\
\text { examination } n=20\end{array}$} & \multirow[b]{2}{*}{$p$-Value $^{1}$} & \multirow[b]{2}{*}{$p$-Value ${ }^{2}$} & \multirow[b]{2}{*}{$p$-Value } \\
\hline & Mean & SD & Mean & SD & Mean & $\mathrm{SD}$ & & & \\
\hline \multicolumn{10}{|c|}{ Longitudinal strain } \\
\hline Global & -16.9 & 3.8 & -17.2 & 2.8 & -17.7 & 2.9 & 0.577 & 0.489 & 0.626 \\
\hline Basal & -21.1 & 4.3 & -20.3 & 4.2 & -20.7 & 3.5 & 0.567 & 0.755 & 0.620 \\
\hline Mid & -17.6 & 5.3 & -18.5 & 5.0 & -19.3 & 5.0 & 0.489 & 0.275 & 0.468 \\
\hline Apical & -16.3 & 5.6 & -17.7 & 4.1 & -17.0 & 4.6 & 0.197 & 0.547 & 0.510 \\
\hline Anterior & -18.4 & 4.3 & -16.7 & 4.8 & -17.0 & 4.2 & 0.089 & 0.155 & 0.624 \\
\hline Anteroseptal & -16.6 & 4.6 & -18.2 & 5.2 & -17.5 & 4.1 & 0.374 & 0.370 & 0.645 \\
\hline Inferoseptal & -19.1 & 3.8 & -20.2 & 4.0 & -20.6 & 4.7 & 0.229 & 0.216 & 0.663 \\
\hline Inferior & -19.8 & 4.7 & -19.4 & 2.9 & -19.6 & 4.8 & 0.854 & 0.645 & 0.933 \\
\hline Inferolateral & -18.6 & 4.3 & -19.0 & 3.4 & -20.6 & 4.6 & 0.704 & 0.093 & 0.473 \\
\hline Anterolateral & -19.3 & 5.0 & -20.0 & 3.5 & -20.1 & 3.7 & 0.528 & 0.479 & 0.889 \\
\hline \multicolumn{10}{|c|}{ Circumferential strain } \\
\hline Global & -29.6 & 7.2 & -27.9 & 5.1 & -30.4 & 6.9 & 0.218 & 0.813 & 0.151 \\
\hline Basal & -23.8 & 6.8 & -21.2 & 5.2 & -24.5 & 7.6 & 0.118 & 0.971 & 0.157 \\
\hline Mid & -29.0 & 8.3 & -29.4 & 6.0 & -31.4 & 6.3 & 0.811 & 0.269 & 0.199 \\
\hline Apical & -36.6 & 13.0 & -36.8 & 11.3 & -36.4 & 11.0 & 0.353 & 0.926 & 0.958 \\
\hline Anterior & -35.1 & 9.5 & -34.3 & 8.5 & -42.5 & 10.3 & 0.455 & 0.021 & 0.008 \\
\hline Anteroseptal & -34.1 & 10.5 & -34.0 & 7.8 & -31.0 & 6.9 & 0.863 & 0.112 & 0.154 \\
\hline Inferoseptal & -31.0 & 7.9 & -28.9 & 7.6 & -30.7 & 6.2 & 0.169 & 0.826 & 0.165 \\
\hline Inferior & -30.7 & 8.5 & -28.2 & 8.1 & -36.0 & 6.3 & 0.279 & 0.006 & 0.002 \\
\hline Inferolateral & -29.1 & 7.9 & -30.1 & 8.0 & -29.0 & 9.0 & 0.704 & 0.093 & 0.473 \\
\hline Anterolateral & -27.5 & 7.9 & -25.6 & 6.6 & -28.7 & 7.9 & 0.146 & 0.592 & 0.239 \\
\hline
\end{tabular}

RT: Radiotherapy. The $p$-Value ${ }^{1}, p$-Value ${ }^{2}$ and $p$-Value ${ }^{3}$ values present the statistical significance of the changes in strain values between baseline and after RT value, baseline and 3 year follow-up examination values and between values measured after RT and at the 3 year follow-up examination, respectively. Significant $p$-values $(p<0.05)$ are shown in bold.

with RSBC, the apical strain increased by $0.7 \pm 5.2 \%(p=0.547)$ at the three-year follow-up compared to the baseline (LSBC $v s$. RSBC change $p=0.007)$. In multivariable analysis, AI use had an independent association with the apical strain change at three-year follow-up in patients with LSBC $(\beta=-4.494$, $p=0.004)$. In patients with RSBC, AI use $(\beta=-6.409, p<0.001)$, mean heart radiation dose $(\beta=2.496, p=0.002)$ and $\mathrm{ACE} / \mathrm{ARB}$ use $(\beta=-3.881, p=0.017)$ had independent associations with the apical strain change at the three-year follow-up. The influence of AI use on apical strain is illustrated in Figure 2. Patients with RSBC using AI had an apical strain decline of 3.6 $\pm 5.2 \%$ while patients not using AI had an increase in apical strain by $3.6 \pm 2.8 \%(p<0.001)$. In the whole study population, patients using AI had a reduction of $3.0 \pm 3.9 \%(p=0.001)$ and $5.4 \pm 5.9 \%$ $(p<0.001)$, while patients not using AI showed an initial increase of $0.1 \pm 4.8 \% \quad(p=0.858)$ and a later decline of $0.3 \pm 4.8 \%(p=0.696)$ after RT and at the three-year follow-up examination, respectively.

Global longitudinal strain. GLS was $-18.0 \pm 3.3 \%$ at the baseline. It declined to $-17.2 \pm 3.1 \%(p=0.028)$ immediately after RT and to $-17.0 \pm 3.0 \%(p=0.015)$ at the three-year followup examination in the whole group. At the post-RT and at the three-year follow-up examinations, GLS was over $15 \%$ lower than at the baseline (GLS15) in fourteen (19\%) and 19 patients (27\%), respectively. The GLS decline was higher in patients with LSBC $v s$. RSBC after RT $(1.1 \pm 2.7 \%$ decline $v s .0 .4 \pm 2.6$ increase, $p=0.040)$ and at the three-year follow-up $(1.7 \pm 2.8 \%$ decline $v s .0 .0 \pm 4.4 \%$ change, $p=0.102)$. GLS15 rates were not different in patients with LSBC and RSBC patients after RT (12 vs. 2 patients, $p=0.324$ ) and at the three-year follow-up (15 vs. 4 patients, $p=0.763)$. In multivariable analysis, AI use ( $\beta=-1.977, p=0.001)$ was independently associated with GLS15. Patients using AI had GLS decline by $2.0 \pm 2.4 \%$ (vs. $0.0 \pm 2.7 \%$ in patients not using $\mathrm{AI}, p=0.001)$ after RT and by $3.2 \pm 4.2 \%$ ( $v s$. $0.2 \pm 3.2 \%$ decline in patients not using AI, $p=0.001$ ) at the three-year follow-up examination. Post-RT GLS15 was observed in 10 patients (14\%) using AI and in 4 patients $(6 \%)$ not using $\mathrm{AI}(p=0.005)$. At the three-year followup examination, $13 \mathrm{AI}$ users $(18 \%)$ and $6(9 \%)$ of the non-users $(p=0.001)$ had a GLS15.

Circumferential strain and rotation of the left ventricle. PostRT, there were no significant changes in the circumferential strain neither in patients with LSBC nor in those with RSBC. However, at the three-year follow-up examination, regional 


\section{BASELINE TO RADIOTHERAPY}
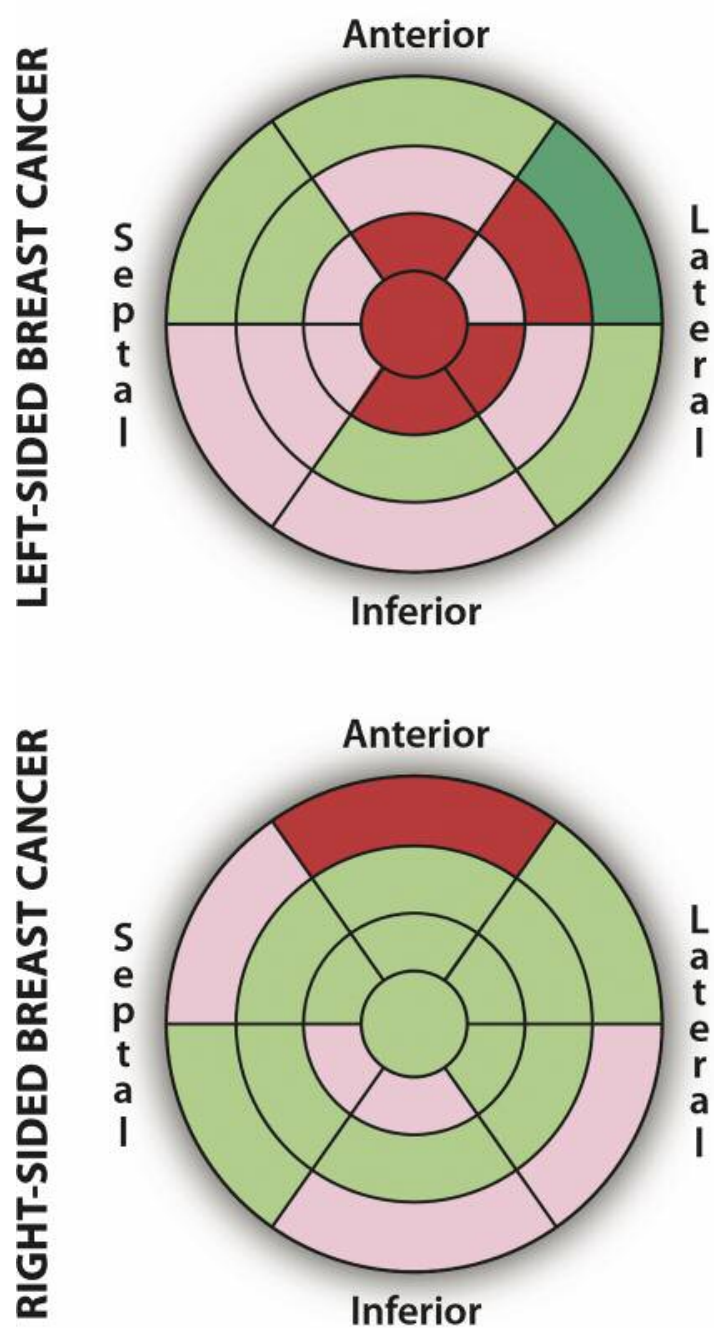

BASELINE TO 3Y CONTROL
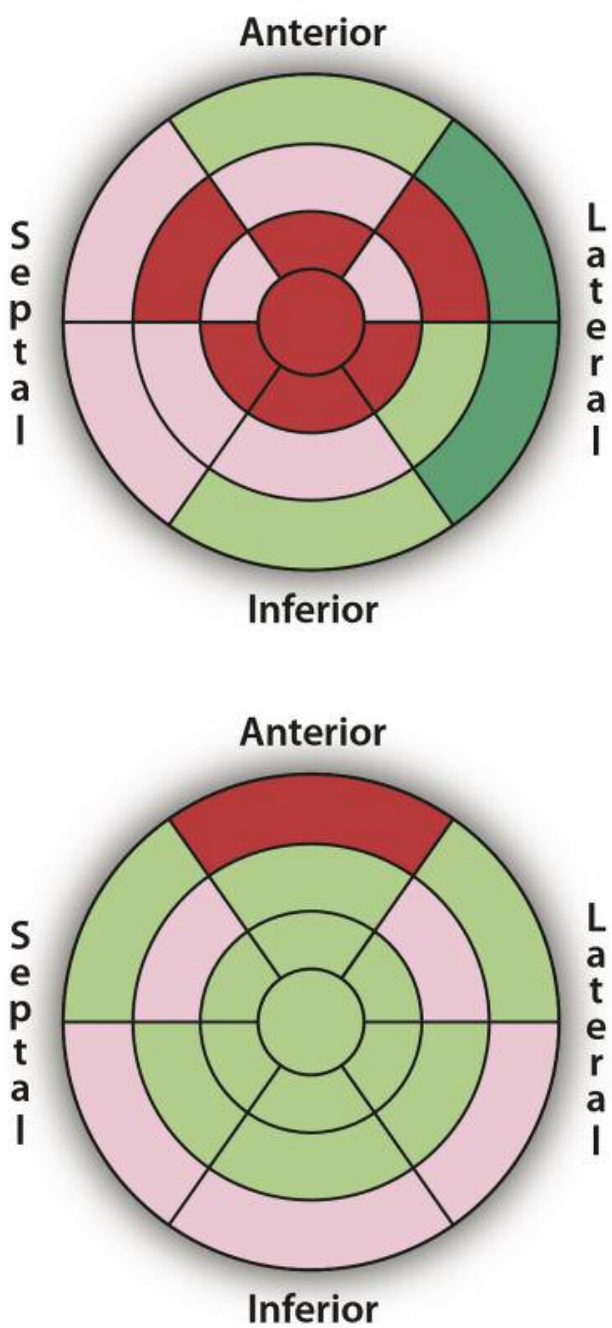

Figure 1. Segmental changes of the left ventricle in longitudinal strain after radiotherapy (figures on the left) and at the three-year follow-up (figures on the right). The red color shows segments with worsening function and green those with better function. The darker colors show segments with statistically significant changes $(p<0.05)$. Patients with left-sided breast cancer are shown on the top row and patients with right-sided breast cancer on the bottom row.

changes were observed in both groups. In patients with LSBC, basal, anterior, inferoseptal and inferior regions presented increased function, while anteroseptal regions presented declined function (Table II). Patients with RSBC had an increase in the anterior and inferior segments (Table III).

The changes in rotation of the LV are shown in Table IV. Patients with LSBC had no significant changes in LV rotation, while patients with RSBC had a significant decline in basal rotation, as well as delayed rotation both in the basal and apical segments.

Conventional echocardiography. The results of the conventional echocardiography measurements are displayed in Table V. The changes were more prevalent in patients with LSBC both after RT and at the three-year follow-up examination.

\section{Discussion}

This study demonstrated that the initial RT-induced changes not only persisted, but they were also aggravated at threeyear follow-up. Patients with LSBC had an apical and anteroseptal deterioration that was exaggerated at the threeyear follow-up examination, while the three-year changes were most prominent in circumferential function and in the rotation of $\mathrm{LV}$ in patients with RSBC. 
A

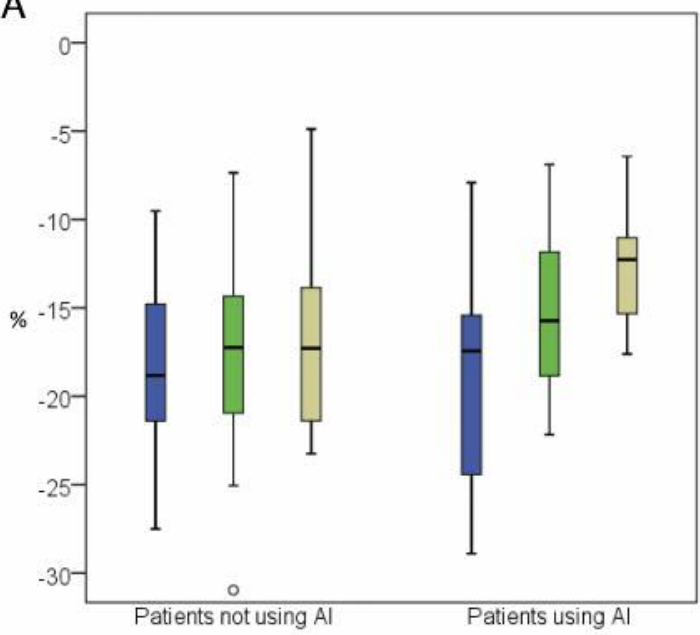

$\mathrm{B}$

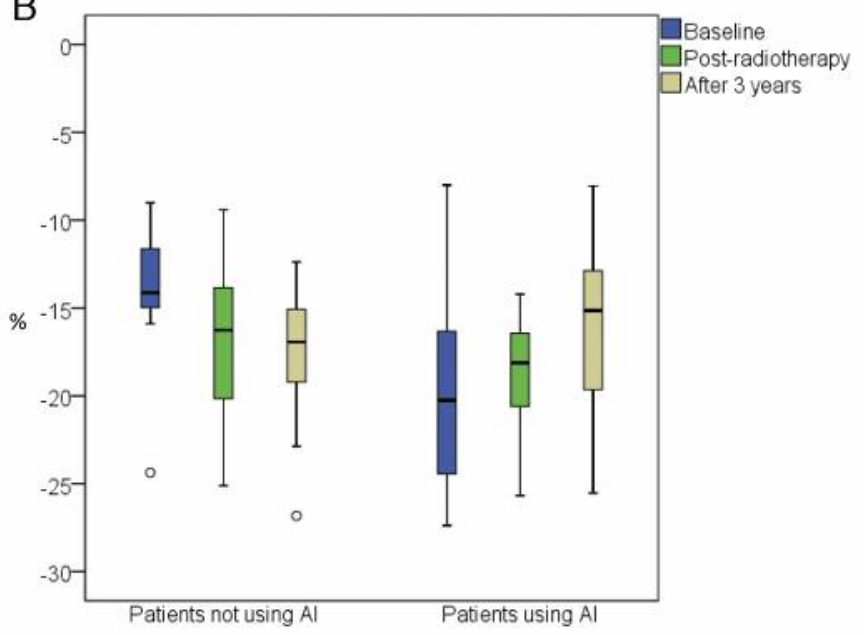

Figure 2. Changes in apical strain in the follow-up according to breast cancer laterality and the use of aromatase inhibitors. Patients with leftsided breast cancer are shown on the left side (A) and patients with right-sided breast cancer on the right side (B). The box plots are colored with blue, green and yellow for baseline, post-radiotherapy and three-year follow-up studies, respectively. Patients not using aromatase inhibitors display a marginal strain decline in patients with left-sided breast cancer, while patients with right-sided breast cancer display an increasing function. Patients using aromatase inhibitors have a significant apical functional decline in both groups.

Table IV. Changes in the left vetricular rotation after breast cancer radiotherapy.

\begin{tabular}{|c|c|c|c|c|c|c|c|c|c|}
\hline & \multicolumn{2}{|c|}{ Baseline } & \multicolumn{2}{|c|}{ After RT } & \multicolumn{2}{|c|}{3 years control } & \multirow[b]{2}{*}{$p$-Value ${ }^{1}$} & \multirow[b]{2}{*}{$p$-Value ${ }^{2}$} & \multirow[b]{2}{*}{$p$-Value ${ }^{3}$} \\
\hline & $\mathrm{Md}$ & [Q1, Q3] & Md & [Q1, Q3] & $\mathrm{Md}$ & [Q1, Q3] & & & \\
\hline \multicolumn{10}{|c|}{$\begin{array}{l}\text { Left-sided breast cancer } \\
(\mathrm{n}=61)\end{array}$} \\
\hline Basal rotation $\left({ }^{\circ}\right)$ & -10.5 & {$[-13.0,-7.6]$} & -10.1 & {$[-13.2,-7.1]$} & -8.8 & {$[-13.0,-6.5]$} & 0.862 & 0.313 & 0.462 \\
\hline Time BR (ms) & 344 & {$[288,426]$} & 383 & {$[311,443]$} & 364 & {$[297,459]$} & 0.294 & 0.660 & 0.806 \\
\hline Apical rotation $\left({ }^{\circ}\right)$ & 5.8 & {$[3.8,10.9]$} & 8.0 & {$[4.4,10.9]$} & 7.4 & {$[4.0,11.2]$} & 0.356 & 0.739 & 0.436 \\
\hline Time AR (ms) & 379 & {$[289,455]$} & 392 & {$[313,469]$} & 357 & {$[315,462]$} & 0.735 & 0.861 & 0.889 \\
\hline Twist $\left({ }^{\circ}\right)$ & 16.2 & {$[12.6,19.0]$} & 16.5 & {$[12.3,23.7]$} & 16.2 & {$[11.2,21.2]$} & 0.285 & 0.524 & 0.296 \\
\hline \multicolumn{10}{|c|}{$\begin{array}{l}\text { Right-sided breast cancer } \\
(\mathrm{n}=20)\end{array}$} \\
\hline Basal rotation $\left({ }^{\circ}\right)$ & -9.5 & {$[-12.6,-7.1]$} & -8.7 & {$[-12.6,-4.2]$} & -7.8 & {$[-9.7,-5.4]$} & 0.295 & $\mathbf{0 . 0 3 0}$ & 0.212 \\
\hline Time BR (ms) & 316 & {$[246,448]$} & 331 & {$[208,450]$} & 397 & {$[296,539]$} & 0.809 & 0.070 & 0.011 \\
\hline Apical rotation $\left({ }^{\circ}\right)$ & 10.1 & {$[3.9,16.0]$} & 8.1 & {$[4.0,12.0]$} & 8.7 & {$[5.9,15.2]$} & 0.231 & 0.469 & 0.306 \\
\hline Time AR (ms) & 334 & {$[245,469]$} & 325 & {$[260,423]$} & 401 & {$[299,483]$} & 0.420 & 0.049 & 0.035 \\
\hline Twist $\left(^{\circ}\right)$ & 18.0 & {$[14.3,25.4]$} & 15.0 & {$[12.5,19.8]$} & 16.5 & {$[14.7,23.4]$} & 0.227 & 0.629 & 0.421 \\
\hline
\end{tabular}

RT: Radiotherapy; Time BR and AR, time of peak basal and apical rotation adjusted to heart rate. Twist is calculated as the difference between maximal basal and apical rotations. The $p$-Value ${ }^{1}, p$-Value ${ }^{2}$ and $p$-Value ${ }^{3}$ present statistical significance of the changes in the strain values between baseline and after RT value, baseline and at the 3 year follow-up examination values and between values measured after RT and at the 3 year followup examination, respectively. Significant $p$-values $(p<0.05)$ are shown in bold.

Radiotherapy-induced changes. Post-RT tissue changes have been well described in previous studies by Fajardo and Khan $(10,11)$. Ionization leads to inflammatory changes within minutes, which subsides within weeks after cessation of RT. Thereafter, endothelial damage leads to capillary rarefication, and a fibrotic cascade is initiated (12).
Likewise, the initial cardiac changes are inflammatory followed by a latent phase (2). The early changes, though currently rare, include pericardial irritation with pericarditis and fluid accumulation. In the latent phase between the inflammatory period and late clinical fibrotic phase, signs of capillary rarefication and initial myocardial fibrotic 
Tuohinen et al: Radiotherapy-induced Strain Changes in Three-year Follow-up

Table V. Conventional echocardiography measurements at baseline, after radiotherapy and at 3 year follow-up examination.

\begin{tabular}{|c|c|c|c|c|c|c|c|c|c|}
\hline & \multicolumn{2}{|c|}{ Baseline } & \multicolumn{2}{|c|}{ After RT } & \multicolumn{2}{|c|}{3 years control } & \multirow[b]{2}{*}{$p$-Value $^{1}$} & \multirow[b]{2}{*}{$p$-Value ${ }^{2}$} & \multirow[b]{2}{*}{$p$-Value 3} \\
\hline & Mean & SD & Mean & SD & Mean & SD & & & \\
\hline \multicolumn{10}{|c|}{$\begin{array}{l}\text { Left-sided breast cancer } \\
(\mathrm{n}=61)\end{array}$} \\
\hline \multicolumn{10}{|l|}{ Structures } \\
\hline LVEDD (mm) & 45.1 & 4.1 & 44.7 & 3.9 & 45.2 & 4.4 & 0.157 & 0.904 & 0.316 \\
\hline LVEDS (mm) & 30.3 & 3.4 & 30.0 & 3.6 & 30.2 & 3.5 & 0.462 & 0.717 & 0.735 \\
\hline LV mass $(\mathrm{g})^{*}$ & 152 & {$[134,174]$} & 165 & {$[139,186]$} & 161 & {$[129,177]$} & 0.017 & 0.487 & 0.009 \\
\hline $\mathrm{RV}$ basal (mm) & 34.1 & 5.0 & 33.6 & 4.5 & 35.0 & 4.2 & 0.340 & 0.267 & 0.038 \\
\hline \multicolumn{10}{|l|}{ Systole } \\
\hline LVEF $(\%)$ & 65 & 7 & 65 & 7 & 59 & 7 & 0.810 & $<0.001$ & $<0.001$ \\
\hline TAPSE (mm) & 24.2 & 3.9 & 22.3 & 4.0 & 23.3 & 4.3 & $<0.001$ & 0.086 & 0.051 \\
\hline \multicolumn{10}{|c|}{ Diastole and filling pressures } \\
\hline LAVI (ml/m²) & 33 & 8 & 32 & 8 & 35 & 9 & 0.432 & 0.036 & $<0.001$ \\
\hline Mitral E (cm/s) & 72 & 15 & 69 & 14 & 70 & 17 & 0.015 & 0.258 & 0.612 \\
\hline Mitral dt (ms) & 234 & 42 & 242 & 47 & 246 & 62 & 0.132 & 0.175 & 0.638 \\
\hline Mitral ea-ratio* & 0.95 & {$[0.77,1.06]$} & 0.88 & {$[0.75,1.13]$} & 0.87 & {$[0.77,1.13]$} & 0.444 & 0.742 & 0.795 \\
\hline Mitral Ee'-ratio* & 8.8 & {$[7.2,10.9]$} & 8.5 & {$[7.1,10.0]$} & 8.6 & {$[7.1,10.4]$} & 0.183 & 0.310 & 0.242 \\
\hline $\operatorname{Tr} \mathrm{gr}(\mathrm{mmHg})$ & 21.5 & 5.6 & 21.4 & 4.7 & 23.5 & 6.0 & 0.677 & 0.011 & 0.012 \\
\hline IVC (mm) & 15.7 & 3.6 & 14.6 & 3.4 & 15.3 & 4.1 & 0.024 & 0.474 & 0.183 \\
\hline $\operatorname{vIVC}(\%)^{*}$ & 60 & {$[52,70]$} & 62 & {$[54,73]$} & 55 & {$[41,68]$} & 0.132 & 0.013 & 0.001 \\
\hline \multicolumn{10}{|c|}{$\begin{array}{l}\text { Right-sided breast cancer } \\
(\mathrm{n}=20)\end{array}$} \\
\hline \multicolumn{10}{|c|}{ Structures } \\
\hline LVEDD (mm) & 43.8 & 4.6 & 43.8 & 3.9 & 44.1 & 4.7 & 0.896 & 0.544 & 0.679 \\
\hline LVEDS (mm) & 29.7 & 3.2 & 29.3 & 3.4 & 30.5 & 3.2 & 0.428 & 0.098 & 0.093 \\
\hline LV mass $(\mathrm{g})^{*}$ & 146 & {$[125,182]$} & 158 & {$[136,208]$} & 146 & {$[123,193]$} & 0.017 & 0.970 & 0.067 \\
\hline RV basal (mm) & 34.3 & 6.0 & 33.6 & 5.7 & 35.0 & 4.9 & 0.522 & 0.489 & 0.182 \\
\hline \multicolumn{10}{|l|}{ Systole } \\
\hline $\operatorname{LVEF}(\%)$ & 64 & 10 & 66 & 6 & 59 & 7 & 0.616 & 0.048 & $<0.001$ \\
\hline TAPSE $(\mathrm{mm})$ & 23.9 & 5.4 & 22.5 & 5.2 & 22.7 & 4.2 & 0.141 & 0.186 & 0.917 \\
\hline \multicolumn{10}{|c|}{ Diastole and filling pressures } \\
\hline $\operatorname{LAVI}\left(\mathrm{ml} / \mathrm{m}^{2}\right)$ & 30 & 9 & 31 & 7 & 32 & 10 & 0.784 & 0.178 & 0.174 \\
\hline Mitral E (cm/s) & 78 & 19 & 72 & 18 & 71 & 18 & 0.041 & 0.033 & 0.671 \\
\hline Mitral dt (ms) & 211 & 42 & 243 & 51 & 227 & 55 & 0.011 & 0.255 & 0.362 \\
\hline Mitral Ea-ratio* & 1.02 & {$[0.78,1.23]$} & 1.00 & {$[0.69,1.09]$} & 0.87 & {$[0.70,1.08]$} & 0.279 & 0.044 & 0.575 \\
\hline Mitral Ee'-ratio* & 10.1 & {$[7.6,12.4]$} & 9.3 & {$[7.5,11.7]$} & 8.9 & {$[7.7,11.1]$} & 0.970 & 0.940 & 0.823 \\
\hline $\operatorname{Tr} \operatorname{gr}(\mathrm{mmHg})$ & 23.0 & 6.9 & 20.6 & 6.1 & 24.9 & 7.6 & 0.025 & 0.125 & 0.031 \\
\hline IVC (mm) & 16.5 & 3.8 & 16.3 & 3.0 & 16.2 & 4.1 & 0.767 & 0.777 & 0.949 \\
\hline $\operatorname{vIVC}(\%)^{*}$ & 61 & {$[43,73]$} & 52 & {$[39,61]$} & 46 & {$[41,57]$} & 0.145 & 0.021 & 0.411 \\
\hline
\end{tabular}

LVEDD and LVESD: Left ventricular end-diastolic and end-systolic diamerters, respectively; LV: left ventricular; RV: right ventricular; LVEF: left ventricular ejection fraction; TAPSE: tricuspid annular plane systolic excursion; LAVI: left atrial volume indexed to body surface area; Mitral E, dt, Ea and Ee': Mitral inflow early diastolic velocity, declaration time of the early inflow, the ratio between early inflow and late inflow velocities and the ratio between early mitral inflow velocity and averaged pulsed tissue Doppler early diastolic velocities derived from basal anterior, septal, posterior and lateral LV walls, respectively; IVC and cIVC: inferior vena cava maximal diameter and its variation, respectively. *marks parameters with non-normal distribution. They are presented as medians with [Q1, Q3]. The $p$-Value ${ }^{1}, p$-Value ${ }^{2}$ and $p$-Value ${ }^{3}$ present statistical significance of the differences in strain values between baseline and after RT value, baseline and at 3 year follow-up values and between values measured after RT and value at the 3 year follow examination, respectively. Significant $p$-values $(p<0.05)$ are shown in bold.

changes are induced (12). They can be detected as perfusion defects (myocardial perfusion imaging) or as subclinical myocardial functional changes (echocardiography) $(13,14)$. Late emerging fibrotic sequelae lead to coronary obstruction, retraction and calcification of the heart valves, and pericardial and myocardial fibrosis leading to constriction and diastolic dysfunction as well as conduction abnormalities $(2,3)$.

Global longitudinal strain. GLS is an early and sensitive marker of LV functional decline over a wide range of diseases (15-17). In cancer patients receiving chemotherapy, an early 
GLS decline has been associated with later LVEF deterioration (8). A $15 \%$ change from the initial value is considered to be clinically significant (4). Changes in LV strain after RT have been described earlier, but their prognostic impact is unclear $(8,9)$. In our patients, the initial GLS change persisted in the three-year follow-up, which may implicate permanent damage. Even more important and worrying is our finding that the proportion of patients with GLS15 increased during the follow-up period. In addition, the mean LVEF was lower at the three-year follow-up than at the baseline. This decline, however, was clinically insignificant and falls into limits of LVEF general variability, but the finding is in concordance with the changes in GLS. The initial strain changes may have been related to the early inflammatory reaction, whereas persisting, and progressive changes at the three-year followup examination may indicate the presence of a more permanent fibrotic process.

Regional longitudinal and circumferential strain changes according to breast cancer side. Both patients with LSBC and RSBC displayed further evolution of the initial post-RT changes at the three-year follow-up examination but in a different way. The patients with LSBC had reductions of strain in the areas where RT fields affected the heart, mainly in the antero-apical regions. At the three-year follow-up, the longitudinal strain was even more influenced in these regions. In general, circumferential strain increased, possibly as a compensatory mechanism, except for the anteroseptal regions at the three-year follow-up examination in patients with LSBC. This indicates that the impact of RT is more severe and progressive on the anteroseptal parts of the heart.

The impact of RT on cardiac function was subtler in patients with RSBC. The longitudinal strain was affected only at the basal anterior segment. However, circumferential strain increased with a similar pattern as in patients with LSBC. Furthermore, basal rotation diminished and both apical and basal rotations were delayed. Changes in LV rotation have been observed at the early phase of many cardiac diseases, and they even precede changes in longitudinal and circumferential strain (18). Aging, hypertension, hypertrophic cardiomyopathy and aortic stenosis are all characterized by increased apical rotation and delayed rotation with longer untwisting (18-22). Anthracycline treatment has induced a decline in both apical and basal rotation along with an overall twist becoming declined and delayed (23). It can be hypothesized that patients with RSBC were affected by a similar process.

The role of $A I$ versus $R T$. In multivariable analysis, AI use had an independent association with several strain changes. AI use inhibits the final pathway of estrogen metabolism, which has been shown to be detrimental to myocardial function and cardiovascular prognosis $(24,25)$. Whether this negative effect seen in our patients is a reversible or long- lasting effect is not clear, while all thirty of our patients who were AI-users $(37 \%)$ were still using AI at the three-year follow-up examination.

Even though the association of cardiac changes was even stronger with AI use than with RT, the effect is probably additive. The timing of initiation of AI treatment was not recorded, but according to clinical practice, at least some of our patients had started their AI treatment prior to RT, and hence, the changes from baseline to post-RT present an additive effect. Furthermore, the distribution of the regional changes presents the effect of RT, and cannot be explained by AI use only. Therefore, in a sense, AI use seems to be at least a sensitizer of the RT-induced effects. However, since the patients were still using AI at the three-year follow-up examination, it is unclear whether the effect of AI on myocardial function is transient or whether the concurrent use of AI during RT actually generates more severe myocardial damage. This issue will be addressed in the later follow-up of this patient group.

\section{Clinical Implications}

The most important clinical finding of our study is that even modern 3D breast cancer RT induced long-standing echocardiographic changes. Taking into account the progressive nature of these changes, it is possible that the patients have an elevated risk of RIHD. In our study, no patient developed symptomatic cardiac diseases during the three-year follow-up. This study population will be followed up further, and the coming years will reveal the later development of these changes and their clinical significance.

\section{Limitations of our Study}

The results of this study present three-year changes and their associations to later clinical events are still unclear. Furthermore, this study was neither designed nor powered to explore the influence of medications, and a specific study to explore the role of $\mathrm{AI}$ in this context is needed.

\section{Conclusion}

STE was able to detect the continuous decline in LV function at three-year follow-up. In patients with LSBC, longitudinal strain in global, regional and segmental levels declined, while patients with RSBC experienced circumferential strain increase and negative changes in rotation. AI use aggravated the changes in strain in both groups.

\section{Conflicts of Interest}

The Authors have no conflicts of interest to declare regarding this study. 


\section{Authors' Contributions}

All Authors have participated in the conception of this study and contributed to the article's content, critically revised the manuscript and approved the final version. TS and PLKL were responsible for recruiting the patients for this study and for calculations of cardiac radiation doses. ST acquired all echocardiographic data and analyzed them. The statistical analysis was performed by ST and HH.

\section{Acknowledgements}

The Authors thank the research nurses Virpi Palomäki, Hanna-Leena Näppilä, Kati Helleharju and Katri Mikkonen for their expert assistance during the study.

\section{References}

1 Barnett GC, West CM, Dunning AM, Elliott RM, Coles CE, Pharoah PD and Burnet NG: Normal tissue reactions to radiotherapy: towards tailoring treatment dose by genotype. Nat Rev Cancer 9(2): 134-142, 2009. PMID: 19148183 . DOI: $10.1038 / \mathrm{nrc} 2587$

2 Lancellotti P, Nkomo VT, Badano LP, Bergler J, Bogaert J, Davin L, Cosyns B, Coucke P, Dulgheru R, Edvardsen T, Gaemperli O, Galderisi M, Griffin B, Heidenreich PA, Nieman K, Plana JC, Port SC, Scherrer-Crosbie M, Schwartz RG, Sebag IA, Voigt JU, Wann $\mathrm{S}$ and Yang PC; European Society of Cardiology Working Groups on Nuclear Cardiology and Cardiac Computed Tomography and Cardiovascular Magnetic Resonance; American Society of Nuclear Cardiology; Society for Cardiovascular Magnetic Resonance; Society of Cardiovascular Computed Tomography: Expert consensus for multi-modality imaging evaluation of cardiovascular complications of radiotherapy in adults: a report from the European Association of Cardiovascular Imaging and the American Society of Echocardiography. Eur Heart J Cardiovasc Imaging 14(12): 721740, 2013. PMID: 23847385. DOI: $10.1093 /$ ehjci/jet123

3 Jaworski C, Mariani JA, Wheeler G and Kaye DM: Cardiac complications of thoracic irradiation. J Am Coll Cardiol 61(23): 2319-2328, 2013. PMID: 23583253. DOI: 10.1016/j.jacc. 2013.01 .090

4 Zamorano JL, Lancellotti P, Rodriguez Munoz D, Aboyans V, Asteggiano R, Galderisi M, Habib G, Lenihan DJ, Lip GYH, Lyon AR, Lopez Fernandez T, Mohty D, Piepoli MF, Tamargo J, Torbicki A and Suter TM; ESC Scientific Document Group. 2016 ESC Position Paper on cancer treatments and cardiovascular toxicity developed under the auspices of the ESC Committee for Practice Guidelines: The Task Force for cancer treatments and cardiovascular toxicity of the European Society of Cardiology (ESC). Eur Heart J 37(36): 2768-2801, 2016. PMID: 27567406. DOI: 10.1093/eurheartj/ehw211

5 Lind PA, Pagnanelli R, Marks LB, Borges-Neto S, Hu C, Zhou SM, Light $\mathrm{K}$ and Hardenbergh $\mathrm{PH}$ : Myocardial perfusion changes in patients irradiated for left-sided breast cancer and correlation with coronary artery distribution. Int J Radiat Oncol Biol Phys 55(4): 914-920, 2003. PMID: 12605969.

6 Erven K, Jurcut R, Weltens C, Giusca S, Ector J, Wildiers H, Van den Bogaert $\mathrm{W}$ and Voigt JU. Acute radiation effects on cardiac function detected by strain rate imaging in breast cancer patients. Int J Radiat Oncol Biol Phys 79(5): 1444-1451, 2011. PMID: 20605341. DOI: 10.1016/j.ijrobp.2010.01.004
7 Tuohinen SS, Skytta T, Poutanen T, Huhtala H, Virtanen V, Kellokumpu-Lehtinen PL and Raatikainen P: Radiotherapyinduced global and regional differences in early-stage left-sided versus right-sided breast cancer patients: speckle tracking echocardiography study. Int J Cardiovasc Imaging 33(4): 463472, 2017. PMID: 27873127. DOI: 10.1007/s10554-016-1021-y

8 Guerra F, Marchesini M, Contadini D, Menditto A, Morelli M, Piccolo E, Battelli N, Pistelli M, Berardi R, Cascinu S and Capucci A: Speckle-tracking global longitudinal strain as an early predictor of cardiotoxicity in breast carcinoma. Support Care Cancer 24(7): 3139-3145, 2016. PMID: 26923461. DOI: 10.1007/s00520-016-3137-y

9 Tang Q, Jiang Y, Xu Y and Xia H: Speckle tracking echocardiography predicts early subclinical anthracycline cardiotoxicity in patients with breast cancer. J Clin Ultrasound 45(4): 222-230, 2017. PMID: 27910996. DOI: 10.1002/ jcu.22434

10 Fajardo LF and Stewart JR: Experimental radiation-induced heart disease. I. Light microscopic studies. Am J Pathol 59(2): 299-316, 1970. PMID: 5443637.

11 Khan MY: Radiation-induced cardiomyopathy. I. An electron microscopic study of cardiac muscle cells. Am J Pathol 73(1): 131-146, 1973. PMID: 4749211.

12 Fajardo LF and Stewart JR: Capillary injury preceding radiationinduced myocardial fibrosis. Radiology 101(2): 429-433, 1971. PMID: 5114783. DOI: 10.1148/101.2.429

13 Hardenbergh PH, Munley MT, Bentel GC, Kedem R, BorgesNeto S, Hollis D, Prosnitz LR and Marks LB: Cardiac perfusion changes in patients treated for breast cancer with radiation therapy and doxorubicin: preliminary results. Int J Radiat Oncol Biol Phys 49(4): 1023-1028, 2001. PMID: 11240243.

14 Erven K, Florian A, Slagmolen P, Sweldens C, Jurcut R, Wildiers $\mathrm{H}$, Voigt JU and Weltens C: Subclinical cardiotoxicity detected by strain rate imaging up to 14 months after breast radiation therapy. Int J Radiat Oncol Biol Phys 85(5): 1172-1178, 2013. PMID: 23149005. DOI: 10.1016/j.ijrobp. 2012.09.022

15 Lowenthal A, Tacy TA, Behzadian F and Punn R: Echocardiographic predictors of early postsurgical myocardial dysfunction in pediatric patients with aortic valve insufficiency. Pediatr Cardiol 34(6): 1335-1343, 2013. PMID: 23389100. DOI: 10.1007/s00246013-0646-Z

16 Chimura M, Onishi T, Tsukishiro Y, Sawada T, Kiuchi K, Shimane A, Okajima K, Yamada S, Taniguchi Y, Yasaka Y and Kawai H: Longitudinal strain combined with delayedenhancement magnetic resonance improves risk stratification in patients with dilated cardiomyopathy. Heart 103(9): 679-686, 2017. PMID: 27799316. DOI: 10.1136/heartjnl-2016-309746

17 Ernande L, Bergerot C, Girerd N, Thibault H, Davidsen ES, Gautier Pignon-Blanc P, Amaz C, Croisille P, De Buyzere ML, Rietzschel ER, Gillebert TC, Moulin P, Altman M and Derumeaux G: Longitudinal myocardial strain alteration is associated with left ventricular remodeling in asymptomatic patients with type 2 diabetes mellitus. J Am Soc Echocardiogr 27(5): 479-488, 2014. PMID: 24508363. DOI: 10.1016/ j.echo.2014.01.001

18 Celic V, Tadic M, Suzic-Lazic J, Andric A, Majstorovic A, Ivanovic B, Stevanovic P, Iracek O and Scepanovic R: Two- and threedimensional speckle tracking analysis of the relation between myocardial deformation and functional capacity in patients with systemic hypertension. Am J Cardiol 113(5): 832-839, 2014. PMID: 24528615. DOI: 10.1016/j.amjcard. 2013.11.031 
19 Kaku K, Takeuchi M, Tsang W, Takigiku K, Yasukochi S, Patel AR, Mor-Avi V, Lang RM and Otsuji Y: Age-related normal range of left ventricular strain and torsion using threedimensional speckle-tracking echocardiography. J Am Soc Echocardiogr 27(1): 55-64, 2014. PMID: 24238753. DOI: 10.1016/j.echo.2013.10.002

20 Candan O, Gecmen C, Kalayci A, Bayam E, Guner A, Gunduz S, Cersit S and Ozkan M: Left ventricular twist in hypertrophic cardiomyopathy: Predictor of nonsustained ventricular tachycardia. Herz 44(3): 238-246, 2019. PMID: 29038823. DOI: 10.1007/s00059-017-4633-7

21 Tumenbayar M, Yamaguchi K, Yoshitomi H, Endo A and Tanabe $\mathrm{K}$ : Increased apical rotation in patients with severe aortic stenosis assessed by three-dimensional speckle tracking imaging. J Echocardiogr 16(1): 28-33, 2018. PMID: 28801894. DOI: $10.1007 / \mathrm{s} 12574-017-0347-3$

22 Feyz L, van Dalen BM, Geleijnse ML, Van Mieghem NM, van Domburg RT and Daemen J: Effect of catheter-based renal denervation on left ventricular function, mass and (un)twist with two-dimensional speckle tracking echocardiography. J Echocardiogr 15(4): 158-165, 2017. PMID: 28497431. DOI: $10.1007 / \mathrm{s} 12574-017-0336-6$
23 Song F, Kang Y, Zhang C, Xu Y, Shi J, Guo Y, Zhang Q, Shu X and Cheng L: The early variation of left ventricular twisting function in patients with lymphoma received anthracycline therapy assessed by three-dimensional speckle tracking echocardiography. Cardiol J 24(5): 484-494, 2017. PMID: 28353310. DOI: $10.5603 /$ CJ.a2017.0035

24 Abdel-Qadir H, Amir E, Fischer HD, Fu L, Austin PC, Harvey PJ, Rochon PA, Lee DS and Anderson GM: The risk of myocardial infarction with aromatase inhibitors relative to tamoxifen in post-menopausal women with early stage breast cancer. Eur J Cancer 68: 11-21, 2016. PMID: 27693889. DOI: 10.1016/j.ejca.2016.08.022

25. Foglietta J, Inno A, de Iuliis F, Sini V, Duranti S, Turazza M, Tarantini L and Gori S: Cardiotoxicity of Aromatase Inhibitors in Breast Cancer Patients. Clin Breast Cancer 17(1): 11-17, 2017. PMID: 27561703. DOI: 10.1016/j.clbc.2016.07.003

Received May 12, 2019

Revised June 9, 2019

Accepted June 12, 2019 